\title{
The DQF-COSY NMR Experiment, a Way to Detect Small J Couplings in the Case of Fast Relaxing Nuclei: Application to ${ }^{59} \mathrm{Co}$ in the Tetrahedral Mixed-Metal Cluster $\mathrm{HRuCo}_{3}(\mathrm{CO})_{11}\left(\mathrm{PPh}_{3}\right)$
}

\author{
Jacky Rosé1, Pierre Kempgens ${ }^{2 *}$ \\ ${ }^{1}$ Laboratoire de Chimie de Coordination, Institut de Chimie (UMR 7177 CNRS), Université de Strasbourg, \\ Strasbourg, France \\ ${ }^{2}$ Department of Chemistry, Rhodes University, Grahamstown, South Africa \\ Email: ${ }^{*}$ P.Kempgens@ru.ac.za
}

Received 30 April 2014; revised 1 June 2014; accepted 11 June 2014

Copyright (C 2014 by authors and OALib.

This work is licensed under the Creative Commons Attribution International License (CC BY).

http://creativecommons.org/licenses/by/4.0/

(c) (i) Open Access

\section{Abstract}

The first investigation and analysis of ${ }^{59} \mathrm{Co} 2 \mathrm{D}$ NMR homonuclear chemical shift correlation spectra for a ruthenium-based tetrahedral mixed-metal cluster $\mathrm{HRuCo}_{3}(\mathrm{CO})_{11}\left(\mathrm{PPh}_{3}\right)$ are reported. For this cluster in solution and by contrast to the conventional COSY NMR experiment, the doublequantum filtered (DQF) COSY NMR spectrum proves the existence of a scalar coupling constant between ${ }^{59} \mathrm{Co}$ nuclei. In order to obtain a value of this coupling, the $2 \mathrm{D}$ COSY spectrum for a threespin $7 / 2 \mathrm{AX}_{2}$ system has been simulated by numerical density matrix calculations. The comparison between experimental and theoretical 2D NMR COSY spectra gives a spin-coupling constant $\left|{ }^{1} \mathrm{~J}\left({ }^{59} \mathrm{Co}^{-59} \mathrm{Co}\right)\right|<300 \mathrm{~Hz}$ for this cluster.

\section{Keywords}

NMR, Cobalt-59, 2D COSY and DQF-COSY, Scalar Couplings, Tetrahedral Mixed-Metal Cluster

Subject Areas: Computational Chemistry, Inorganic Chemistry

\footnotetext{
${ }^{*}$ Corresponding author.
}

How to cite this paper: Rosé, J. and Kempgens, P. (2014) The DQF-COSY NMR Experiment, a Way to Detect Small J Couplings in the Case of Fast Relaxing Nuclei: Application to ${ }^{59} \mathrm{Co}$ in the Tetrahedral Mixed-Metal Cluster $\mathrm{HRuCO}_{3}(\mathrm{CO})_{11}\left(\mathrm{PPh}_{3}\right)$. Open Access Library Journal, 1: e622. http://dx.doi.org/10.4236/oalib.1100622 


\section{Introduction}

The conventional COSY NMR experiment [1] is an efficient and powerful technique to prove qualitatively the existence of a coupling constant between quadrupolar nuclei. However, most of the investigations performed so far concern nuclei with small quadrupole moments such as ${ }^{11} \mathrm{~B}$ [2]-[10], ${ }^{51} \mathrm{~V}$ [11], ${ }^{2} \mathrm{H}$ [12], ${ }^{6} \mathrm{Li}[13]-[16]$ and ${ }^{7} \mathrm{Li}$ [14]-[16], whose lines are relatively narrow $(10-150 \mathrm{~Hz})$ in the conventional $1 \mathrm{D}$ spectrum. The DQF-COSY NMR experiment has only been scarcely used in the field of quadrupolar nuclei, and only when the lines were broad in the 1D spectrum [17]-[19]. Recently, we have shown theoretically the superiority of the DQF-COSY NMR experiment when trying to detect and determine relatively small $J$ couplings in the case of fast relaxing nuclei and broad peaks in the quadrupolar nucleus 1D NMR spectrum [20]-[24]. Ideal candidates for such NMR spectroscopic investigations are available in the realm of metal cluster chemistry [25]-[27], as previously shown for $\mathrm{HFeCo}_{3}(\mathrm{CO}) \mathrm{L}$ with $\mathrm{L}=\mathrm{PPh}_{2} \mathrm{H}$ [17], $\mathrm{PPh}_{3}, \mathrm{P}(\mathrm{OMe})_{3}, \mathrm{PCy}_{3}$ [18] and $\mathrm{HFeCo}_{3}(\mathrm{CO})_{10}\left(\mathrm{PCyH}_{2}\right)\left(\mathrm{PPh}_{2}\right)\left[\mathrm{CH}_{2} \mathrm{C}(\mathrm{O}) \mathrm{Ph}\right][19]$.

Tetrahedral mixed-metal clusters containing ruthenium have been shown to have different chemical shifts and line widths in the ${ }^{59}$ Co $1 \mathrm{D}$ NMR spectrum than their iron-based counterparts [28]. The effect of a change in the apical metal (Fe or $\mathrm{Ru}$ ) on the ${ }^{59} \mathrm{Co}$ chemical shifts has been studied in detail on a large number of these clusters [28]. A study of the line widths has clearly shown that the apical atom plays an important role in the electron distribution at the cobalt atom [28]. This is the case for $\mathrm{HRuCo}_{3}(\mathrm{CO})_{11}\left(\mathrm{PPh}_{3}\right)$ (Figure 1) in $\mathrm{CDCl}_{3}$ which is the subject of this paper. Since we have demonstrated experimentally the feasibility of using the DQF-COSY experiment to detect and determine relatively small $\mathrm{J}_{\mathrm{Co}-\mathrm{Co}}$ couplings in an iron-based tetrahedral mixed-metal cluster giving rise to broad lines in the ${ }^{59}$ Co $1 \mathrm{D}$ NMR spectrum $(2.5-4.5 \mathrm{kHz})$ [19], it was of interest to test the method on a ruthenium-based tetrahedral mixed-metal cluster such as $\mathrm{HRuCo}_{3}(\mathrm{CO})_{11}\left(\mathrm{PPh}_{3}\right)$, because the lines in the ${ }^{59}$ Co 1D NMR spectrum are even broader than those for the iron-based analog [28] [29]. Indeed, the linewidths for the iron-based cluster in $\mathrm{CD}_{2} \mathrm{Cl}_{2}$ are $1500 \mathrm{~Hz}$ and $1600 \mathrm{~Hz}$ while the linewidths for the ruthenium-based cluster in $\mathrm{CDCl}_{3}$ are $5100 \mathrm{~Hz}$ and $2900 \mathrm{~Hz}$, keeping in mind that $\mathrm{CD}_{2} \mathrm{Cl}_{2}$ and $\mathrm{CDCl}_{3}$ have comparable viscosities. Furthermore, it was felt interesting to determine the $\mathrm{J}_{\mathrm{Co}-\mathrm{Co}}$ scalar coupling constant and compare its value with those found previously for iron-based tetrahedral mixed-metal clusters. The $\mathrm{J}_{\mathrm{Co}-\mathrm{Co}}$ coupling reported here is the first one for a ruthenium-based tetrahedral mixed-metal cluster.

\section{Theory}

For the conventional COSY experiment, the complex signal may be written as [20]

$$
s^{+}\left(t_{1}, t_{2}\right)=C_{1} \sum_{r, s}^{N} \sum_{\substack{t, u \\ t>u}}^{N} Z_{r, s, t, u} \exp \left(i \Omega_{u, t} t_{1}\right) \exp \left(i \Omega_{s, r} t_{2}\right) \times \exp \left(-t_{1} / T_{2(t, u)}\right) \exp \left(-t_{2} / T_{2(r, s)}\right)
$$

where $C_{1}$ is a constant of proportionality. This last equation is valid for an AX system of any spin $S$. It is also valid for an AMX system of spins $S=7 / 2$. Relaxation was introduced through relaxation of transitions $(t, u)$ and $(r, s)$ during evolution and detection periods, respectively. In this last equation, $N$ is the number of the quantum states of the spin system. The complex intensity $Z_{r, s, t, u}$ is defined by [20]

$$
Z_{r, s, t, u}=S_{s, r}^{+} R_{90 x(r, t)}^{-1} R_{90 x(u, s)} \sigma_{t, u}^{(x)}\left(t_{1}=0\right)=S_{s, r}^{+} R_{90 y(r, t)}^{-1} R_{90 y(u, s)} \sigma_{t, u}^{(x)}\left(t_{1}=0\right)
$$

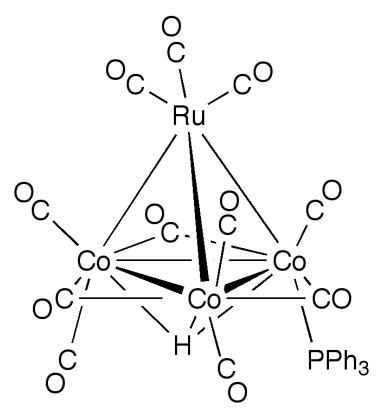

Figure 1. Schematic of the $\mathrm{HRuCo}_{3}(\mathrm{CO})_{11}\left(\mathrm{PPh}_{3}\right)$ cluster. 
The density matrix element $\sigma_{t, u}^{(x)}\left(t_{1}=0\right)$ represents the initial amplitude and phase of a coherence component associated with a transition $t \leftrightarrow u$ at the beginning of the evolution period. The selection rules of observation are represented by the raising operator $S_{s, r}^{+}=S_{x(s, r)}+i S_{y(s, r)}$, where $S_{x}$ and $S_{y}$ are the $x$ and $y$ components of the total angular momentum spin operator. The coherence transfer amplitude which describes the transfer of coherence from transition between two states $\mid t>$ and $\mid u>$ to a transition between two states $|r\rangle$ and $|s\rangle$ is equal to the product of two rotation matrix elements. The peak intensities are determined by the amplitude of coherence transfer, taking into account the limitations imposed by coherence transfer selection rules.

For the DQF-COSY NMR experiment, the complex signal may be written as a function of the same complex coefficients $Z_{r, s, t, u}$ needed to calculate the 2D COSY NMR spectrum of the same spin system [21] [22]

$$
\begin{aligned}
s^{+}\left(t_{1}, t_{2}\right)= & C_{2} \sum_{r, s}^{N} \sum_{\substack{t, u \\
t>u}}^{N} Z_{r, s, t, u}\left[\exp \left(-i \Omega_{u, t} t_{1}\right) \exp \left(-2 i \Phi_{r, s, t, u}\right)-\exp \left(-i \Omega_{N+1-r, N+1-s} t_{1}\right)\right] \times \\
& \exp \left(i \Omega_{s, r} t_{2}\right) \exp \left(-t_{1} / T_{2(t, u)}\right) \exp \left(-t_{2} / T_{2(r, s)}\right)
\end{aligned}
$$

with the symbols having the same meaning as before and $C_{2}$ being a constant of proportionality.

For an AMX system of spin-7/2, there are (512) complex intensities $Z_{r, s, t, u}$ and these factors were calculated numerically with a program written in Fortran 77 . The knowledge of the complex intensities allowed us to expand Equations (1) and (3) and two other programs written in C use the expressions we have obtained to compute the free induction decays for incremented values of $t_{1}$ for the conventional COSY and the DQF-COSY NMR experiments, respectively.

\section{Theoretical Simulations}

Figure 2 and Figure 3 illustrate the effect of the $\mathrm{J}$ coupling constant on the intensities of the peaks, using, in the calculations of $s^{+}\left(t_{1}, t_{2}\right)$ a set of values corresponding to those found experimentally on our tetrahedral cluster. Figures 2(a)-(e) (COSY) and Figures 3(a)-(e) (DQF-COSY) were generated for $\omega_{A}=11475 \mathrm{~Hz}$,

$\omega_{X}=-8820 \mathrm{~Hz}, T_{2 A}=T_{2 X}=100 \mu \mathrm{s}$ and $J=20,40,60,80$ and $100 \mathrm{~Hz}$, respectively. Data were apodized in both dimensions and the data matrix $S\left(\omega_{1}, \omega_{2}\right)$ obtained after 2D Fourier transformation of $s^{+}\left(t_{1}, t_{2}\right)$ in both domains is drawn in the power mode as a contour plot. As expected, these 2D spectra are symmetrical about the diagonal, i.e. $S\left(\omega_{1}, \omega_{2}\right)=S\left(\omega_{2}, \omega_{1}\right)$ and independent of the sign of the coupling constant $\mathrm{J}$.

These simulations show that if small scalar coupling is present between the two nuclei $A$ and $X$ and if the relaxation times $T_{2 A}$ and $T_{2 X}$ are short, it is not possible to detect the coupling with the conventional COSY NMR experiment because the information we are looking for is obscured in the theoretical spectrum by the overlap of the intense diagonal peaks with the very small cross peaks. On the other hand, and as previously mentioned [24], it is possible in the same situation to detect the $\mathrm{J}$ coupling between nuclei $A$ and $X$ with a 2D DQF-COSY NMR experiment, as observed in Figures 3(a)-(f).

\section{Experimental}

The cluster $\mathrm{HRuCo}_{3}(\mathrm{CO})_{11}\left(\mathrm{PPh}_{3}\right)$ (Figure 1), synthesized according to the published procedure [30], was dissolved in $\mathrm{CDCl}_{3} .{ }^{59} \mathrm{Co}$ NMR spectra were measured on a Bruker Avance II 600 spectrometer operating at 142.01 MHz. All spectra were run at room temperature. Chemical shifts are reported downfield from the external reference $\mathrm{Co}(\mathrm{acac})_{3}$ saturated in $\mathrm{CDCl}_{3}$. Experiments were performed with a $\pi / 2$ pulse length of $20 \mu$ s. All experiments were performed with an ${ }^{1} \mathrm{H}(\mathrm{BB}) 5 \mathrm{~mm}$ "inverse" probe-head using the standard Bruker software. Typical parameters were as follows: $S W 1=S W 2=62.5 \mathrm{kHz}$, acquisition time $2.0980 \mathrm{~ms}$, data points $256\left(\mathrm{~F}_{2}\right), 128$ $\left(\mathrm{F}_{1}\right)(\mathrm{COSY}) / 32\left(\mathrm{~F}_{1}\right)(\mathrm{DQF}-\mathrm{COSY})$, recycle delay $40 \mathrm{~ms}$ (COSY)/10ms (DQF-COSY), number of scans 2048 (COSY)/16384 (DQF-COSY), exponential window function with a line broadening of $2000 \mathrm{~Hz}$ and power spectra in both dimensions.

$T_{1}$ relaxation times measurements have been performed on the cluster but due to the very long $\pi / 2$ pulse length and also to the fact that the $T_{1}$ relaxation times are around $100 \mu \mathrm{s}$, it was not possible to determine these relaxation times accurately.

\section{Results and Discussion}

The ${ }^{59} \mathrm{Co}$ NMR spectrum of the cluster $\mathrm{HRuCo}_{3}(\mathrm{CO})_{11}\left(\mathrm{PPh}_{3}\right)$ consists of two resonances having intensities in the 


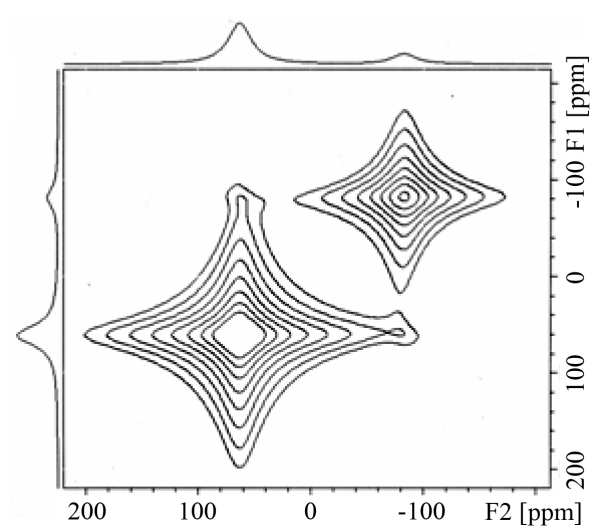

(a)

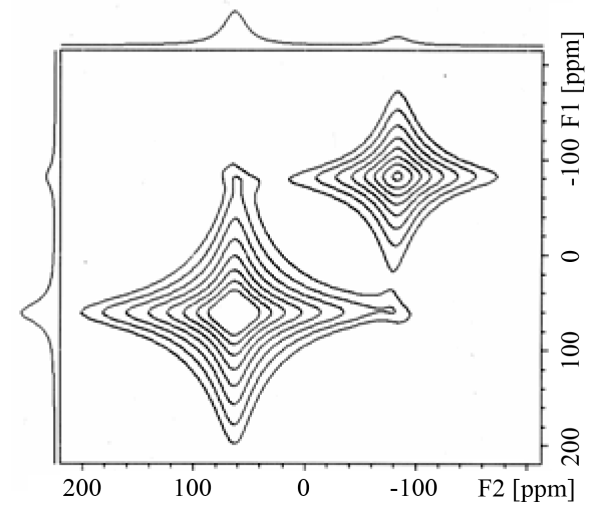

(c)

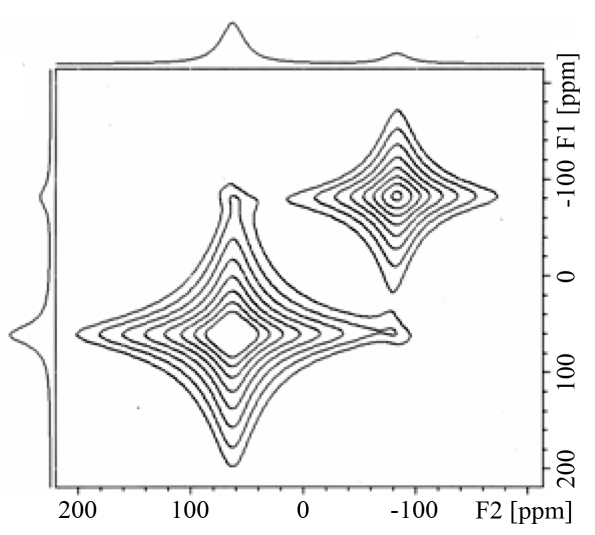

(b)

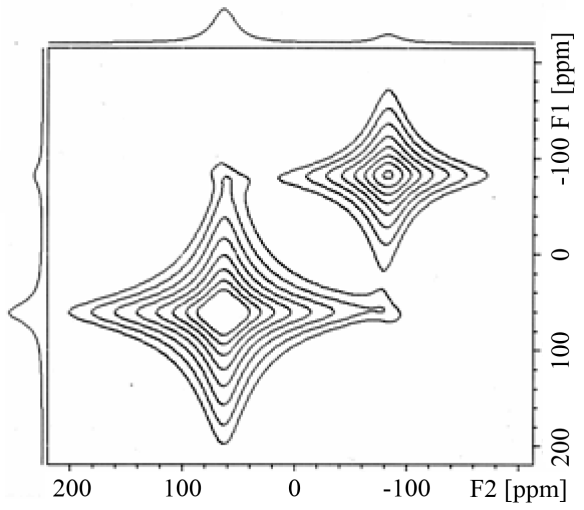

(d)

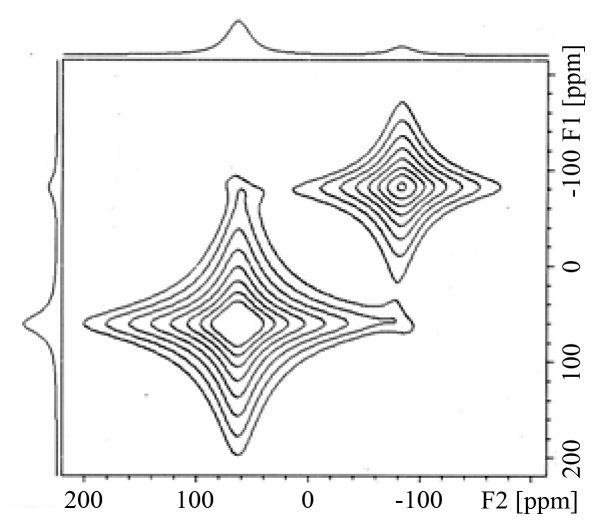

(e)

Figure 2. 2D NMR COSY calculated power spectra with $\omega_{A}=11475 \mathrm{~Hz}, \omega_{X}=-8820 \mathrm{~Hz}, T_{2 A}=$ $T_{2 X}=100 \mu \mathrm{s}$ and (a) $\mathrm{J}=20 \mathrm{~Hz}$ (b) $\mathrm{J}=40 \mathrm{~Hz}$ (c) $\mathrm{J}=60 \mathrm{~Hz}$ (d) $\mathrm{J}=80 \mathrm{~Hz}$ and (e) $\mathrm{J}=100 \mathrm{~Hz}$.

ratio 1:2 (Figure 4). There is no evidence in the $1 \mathrm{D}^{59} \mathrm{Co}$ NMR spectrum for the existence of a J scalar coupling constants between the non-equivalent ${ }^{59} \mathrm{Co}$ nuclei, as previously observed for iron-based tetrahedral mixed-metal clusters [17] [18]. The cobalt nucleus bound to $\mathrm{PPh}_{3}\left(\mathrm{Co}_{1}\right)$ resonates at $-14,888 \mathrm{ppm}$ while the two equivalent cobalt nuclei $\left(\mathrm{Co}_{2}\right)$ are observed at $-15,028 \mathrm{ppm}$. The $T 2$ values of $\mathrm{Co}_{1}$ and $\mathrm{Co}_{2}$ estimated from the line widths are equal to 110 and $60 \mu \mathrm{s}$, respectively, while it was not possible to measure the $T_{1}$ relaxation times because of the very long $\pi / 2$ pulse and at the same time the very short $T_{1}$ relaxation times (around $100 \mu \mathrm{s}$ ). As previously explained for similar clusters [17] [18], there should be a difference between $T_{1}$ and $T_{2}$ for the two cobalt nuclei due to the scalar relaxation of the second kind where $T_{1}$ is different from $T_{2}$ [31]. This mechanism implies the 


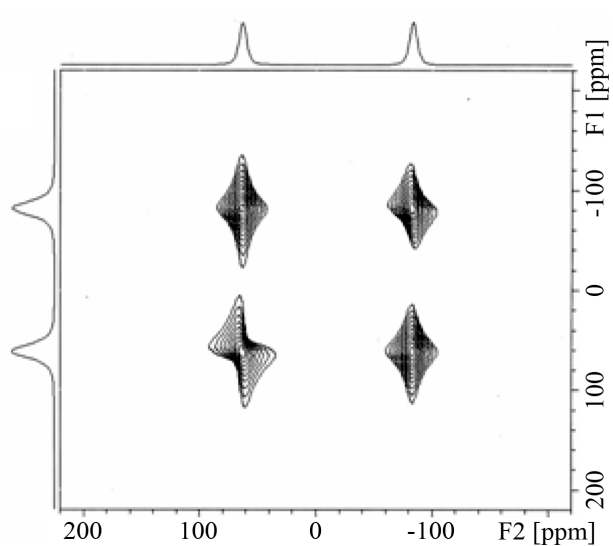

(a)

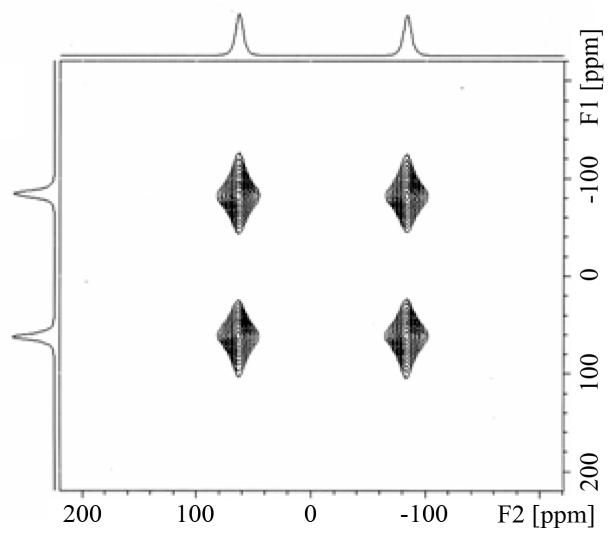

(c)

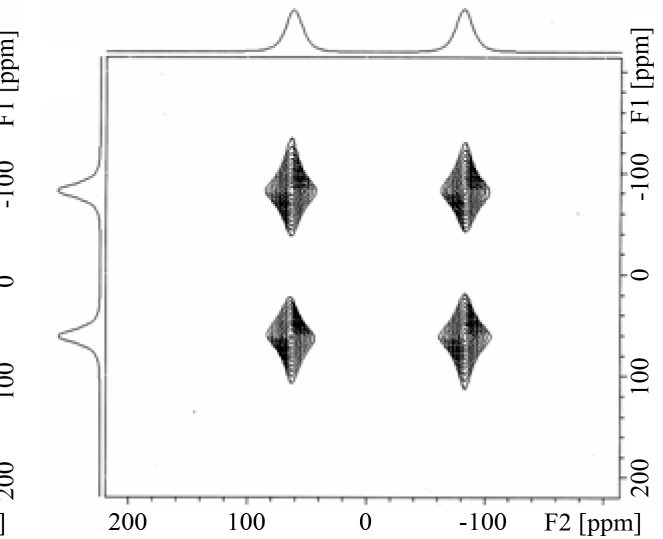

(b)

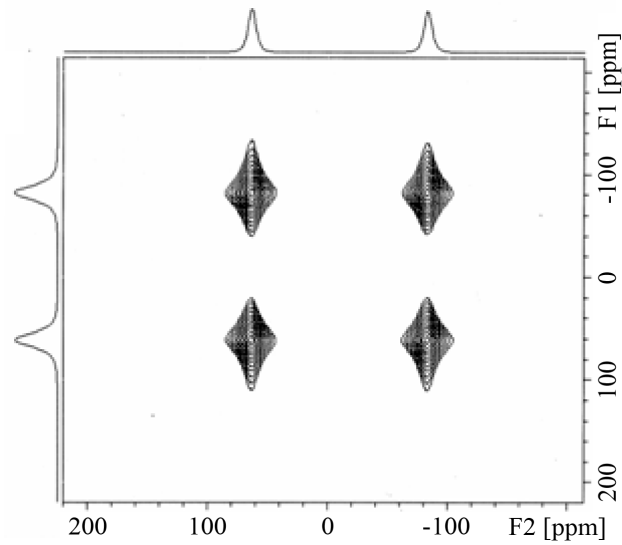

(d)

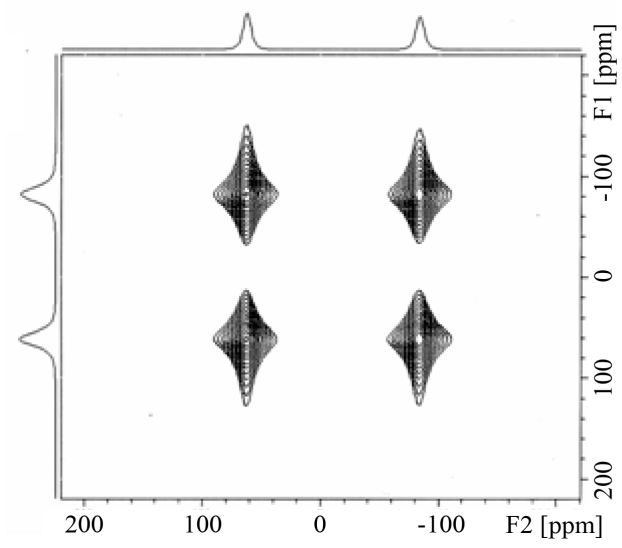

(e)

Figure 3. 2D NMR DQF-COSY calculated power spectra with $\omega_{A}=11475 \mathrm{~Hz}, \omega_{X}=-8820 \mathrm{~Hz}$, $T_{2 A}=T_{2 X}=100 \mu \mathrm{s}$ and (a) $\mathrm{J}=20 \mathrm{~Hz}$ (b) $\mathrm{J}=40 \mathrm{~Hz}$ (c) $\mathrm{J}=60 \mathrm{~Hz}$ (d) $\mathrm{J}=80 \mathrm{~Hz}$ and (e) $\mathrm{J}=100 \mathrm{~Hz}$.

existence of coupling constants and the fact that $T_{1}$ and $T_{2}$ are comparable indicates that the $\mathrm{J}$ coupling in our case, if it exists, is small but hopefully still detectable by using DQF-COSY NMR experiments, as highlighted in the theoretical simulations part of this paper. It was therefore of interest to obtain ${ }^{59} \mathrm{Co} 2 \mathrm{D}$ COSY-type NMR spectra of our cluster.

The 2D ${ }^{59} \mathrm{Co}$ COSY and DQF-COSY NMR spectra are shown in Figure 5(a) and Figure 5(b), respectively. In the 2D COSY NMR spectrum (Figure 5(a)), cross peaks between the two resonances are not visible by contrast 


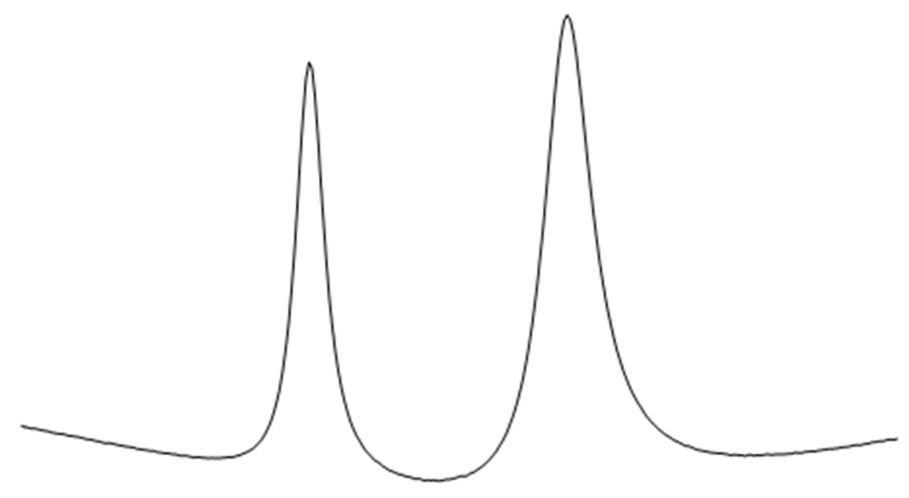

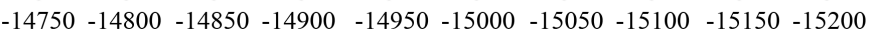
f1 (ppm)

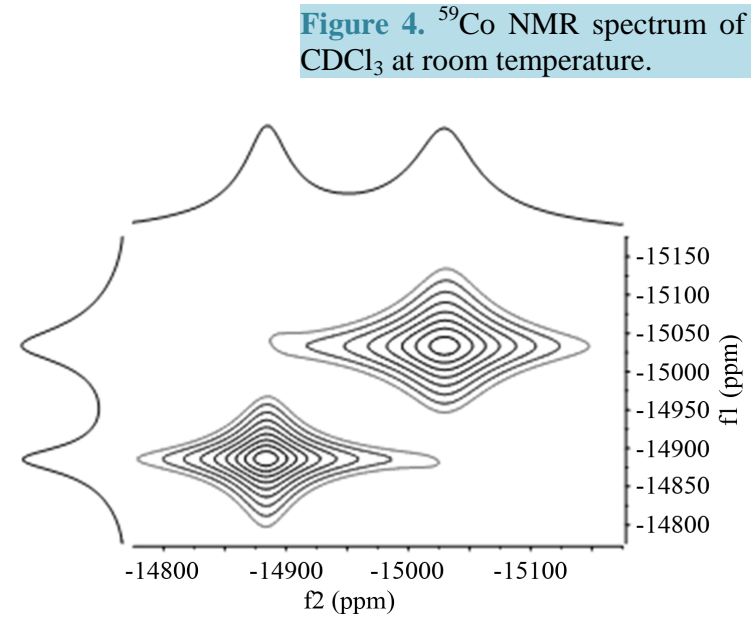

(a)

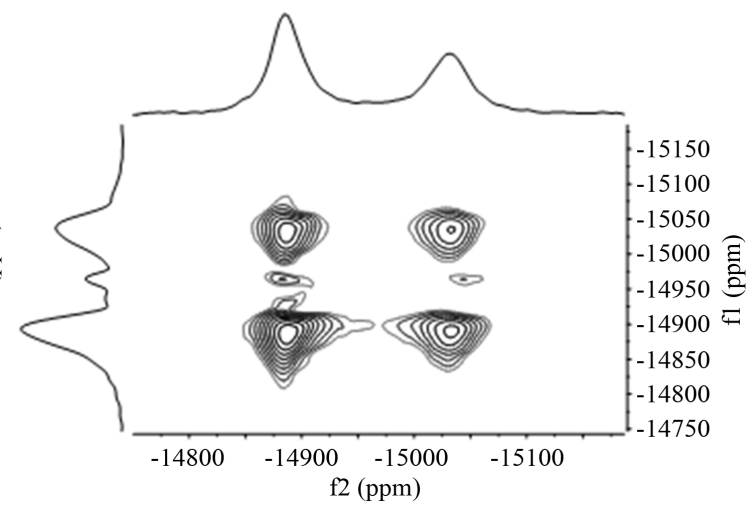

(b)

Figure 5. ${ }^{59} \mathrm{Co} 2 \mathrm{D}$ NMR power spectra of the cluster $\mathrm{HRuCo}_{3}(\mathrm{CO})_{11}\left(\mathrm{PPh}_{3}\right)$ in $\mathrm{CDCl}_{3}$ at room temperature. (a) Experimental COSY NMR spectrum. (b) Experimental DQF-COSY NMR spectrum.

to what happen in the DQF-COSY NMR spectrum (Figure 5(b)). This illustrates very well the fact that it is much easier in the case of quadrupolar nuclei relaxing very quickly to detect a relatively small $\mathrm{J}$ coupling in a 2D DQF-COSY NMR spectrum. In order to obtain a value for the ${ }^{1} \mathrm{~J}\left({ }^{59} \mathrm{Co}-{ }^{59} \mathrm{Co}\right)$ coupling constant, the $2 \mathrm{D}{ }^{59} \mathrm{Co}$ COSY spectrum was analyzed according to the equations given above. In this analysis, it has been assumed that 1 ) the ${ }^{59}$ Co relaxation is described with the assumptions of extreme narrowing and single correlation time, 2) the decay of coherences for nuclei, $A$ and $X$ is described by a single transverse relation time $T_{2 A}$ and $T_{2 X}$, respectively, and 3) the couplings between the ${ }^{31} \mathrm{P}$ and ${ }^{59} \mathrm{Co}$ nuclei (some values of ${ }^{1} \mathrm{~J}_{\mathrm{Co}} \mathrm{P}$ couplings in tetrahedral mixed-metal clusters of general formula $\mathrm{HFeCo}_{3}(\mathrm{CO})_{11} \mathrm{~L}$ have been reported previously in the literature: ${ }^{1} \mathrm{~J}_{\mathrm{Co}-\mathrm{P}}=$ $450 \mathrm{~Hz}$ with $\mathrm{L}=\mathrm{PPh}_{2} \mathrm{H}$ [32] [33], ${ }^{1} \mathrm{~J}_{\mathrm{Co}-\mathrm{P}}=446 \mathrm{~Hz}$ with $\mathrm{L}=\mathrm{PCy}_{2} \mathrm{H}$ [33], ${ }^{1} \mathrm{~J}_{\mathrm{Co}-\mathrm{P}}=573 \mathrm{~Hz}$ with $\mathrm{L}=\mathrm{PPh}_{3}[33]$ and ${ }^{1} \mathrm{~J}_{\mathrm{Co}-\mathrm{P}}=750 \mathrm{~Hz}$ with $\mathrm{L}=\left[\mathrm{P}(\mathrm{OMe})_{3}\right]$ [18] [34]) and between ${ }^{99} \mathrm{Ru}$ and ${ }^{59} \mathrm{Co}$ nuclei (there has been no value of a ${ }^{1} \mathrm{~J}_{\mathrm{Co}-\mathrm{Ru}}$ coupling reported in the literature before, to the best of our knowledge) are neglected. Note that according to our experience, taking into account the coupling between ${ }^{31} \mathrm{P}$ and ${ }^{59} \mathrm{Co}$ nuclei, as was previously done, does not change the final result for the ${ }^{1} \mathrm{~J}\left({ }^{59} \mathrm{Co}-{ }^{59} \mathrm{Co}\right)$ coupling constants [17] [18].

Attempts to analyze this 2D DQF-COSY NMR spectrum (not shown) did not give satisfactory results. This may be due to an irradiation problem because of the very long $\pi / 2$ pulse length of $20 \mu$ s. In this case, it will definitively be useful to use solid-state NMR transmitters and probes and work with very short pulses as previously done [17] [18].

Attempts to analyze the 2D COSY NMR spectrum (not shown) show that the cross peaks start to be visible for ${ }^{1} \mathrm{~J}\left({ }^{59} \mathrm{Co}_{-}{ }^{59} \mathrm{Co}\right)=300 \mathrm{~Hz}$. Therefore, as cross peaks are not visible on the experimental spectrum, this value is 
Table 1. Parameters obtained from the analysis of the $1 \mathrm{D}{ }^{59} \mathrm{Co}$ spectrum of cobalt nuclei $\mathrm{Co}_{1}$ and $\mathrm{Co}_{2}$ in the cluster $\mathrm{HRuCo}_{3}(\mathrm{CO})_{11}\left(\mathrm{PPh}_{3}\right)$ and the $\left.{ }^{1} \mathrm{~J}^{59} \mathrm{Co}-{ }^{59} \mathrm{Co}\right)$ scalar coupling constant determined from the simulation of the ${ }^{59} \mathrm{Co} \mathrm{COSY}$ NMR spectrum.

\begin{tabular}{cccccc} 
& Ligand & $\delta_{\mathrm{co}}^{59}(\mathrm{ppm})$ & $\Delta v_{1 / 2}(\mathrm{~Hz})$ & $T_{2}(\mu \mathrm{s})^{\mathrm{a}}$ & $\left.{ }^{1} \mathrm{~J}^{59} \mathrm{Co}_{\mathrm{i}}{ }^{59} \mathrm{Co}_{\mathrm{j}}\right)(\mathrm{Hz})^{\mathrm{b}}$ \\
\hline $\mathrm{Co}_{1}$ & $\mathrm{PPh}_{3}$ & $-14,888 \pm 10$ & $2870 \pm 200$ & 111 & $(1-2)<300$ \\
$\mathrm{Co}_{2}$ & Unsubstituted & $-15,028 \pm 10$ & $5110 \pm 200$ & 62 & \\
\hline
\end{tabular}

${ }^{\mathrm{a}}$ Calculated from the line width of each signal. ${ }^{\mathrm{b}}$ Determined from the simulation of the ${ }^{59}$ Co COSY NMR spectrum.

an upper limit for the ${ }^{1} \mathrm{~J}\left({ }^{59} \mathrm{Co}-{ }^{59} \mathrm{Co}\right)$ coupling (Table 1$)$. Note that we supposed in the simulations that $T_{1}=T_{2}, T_{2}$ being obtained from the line widths, and this hypothesis is supported by the fact that the $\mathrm{J}_{\text {Co-Co }}$ coupling is small in our case.

It is of interest to compare the value of the ${ }^{1} \mathrm{~J}\left({ }^{59} \mathrm{Co}-{ }^{59} \mathrm{Co}\right)$ coupling constant obtained in this work with those previously determined. The only ones known were determined in iron-based tetrahedral mixed-metal clusters and are surprisingly of the same order of magnitude compared to the ${ }^{1} \mathrm{~J}\left({ }^{59} \mathrm{Co}_{-}{ }^{59} \mathrm{Co}\right)$ coupling determined in this work: ${ }^{1} \mathrm{~J}\left({ }^{59} \mathrm{Co}-{ }^{59} \mathrm{Co}\right)=(115 \pm 20) \mathrm{Hz}$ for $\mathrm{HFeCo}_{3}(\mathrm{CO})_{11}\left(\mathrm{PPh}_{2} \mathrm{H}\right)[17],{ }^{1} \mathrm{~J}\left({ }^{59} \mathrm{Co}_{-}{ }^{59} \mathrm{Co}\right)=140 \mathrm{~Hz}$ for

$\mathrm{HFeCo}_{3}(\mathrm{CO})_{11}\left(\mathrm{PPh}_{3}\right)[18],{ }^{1} \mathrm{~J}\left({ }^{59} \mathrm{Co}-{ }^{59} \mathrm{Co}\right)=(165 \pm 15) \mathrm{Hz}$ for $\mathrm{HFeCo}_{3}(\mathrm{CO})_{11}\left[\mathrm{P}(\mathrm{OMe})_{3}\right][18],{ }^{1} \mathrm{~J}\left({ }^{59} \mathrm{Co}-{ }^{59} \mathrm{Co}\right)=45$ $\mathrm{Hz}$ for $\mathrm{HFeCo}_{3}(\mathrm{CO})_{11}\left(\mathrm{PCy}_{3}\right)[18]$ and ${ }^{1} \mathrm{~J}\left({ }^{59} \mathrm{Co}-{ }^{59} \mathrm{Co}\right)=(600 \pm 150) \mathrm{Hz},{ }^{1} \mathrm{~J}\left({ }^{59} \mathrm{Co}^{59}{ }^{50}\right)=(450 \pm 100) \mathrm{Hz}$, ${ }^{1} \mathrm{~J}\left({ }^{59} \mathrm{Co}-{ }^{59} \mathrm{Co}\right)=(350 \pm 100) \mathrm{Hz}$ for $\mathrm{HFeCo}_{3}(\mathrm{CO})_{10}\left(\mathrm{PCyH}_{2}\right)\left(\mathrm{PPh}_{2}\left[\mathrm{CH}_{2} \mathrm{C}(\mathrm{O}) \mathrm{Ph}\right]\right)$ [19]. This could be explained by the similarities between the phosphorous ligands used. Note that large differences were also observed for ${ }^{1} \mathrm{~J}\left({ }^{59} \mathrm{Co}^{31} \mathrm{P}\right)$ scalar coupling constants in iron-based tetrahedral mixed-metal clusters [18] [32]-[35].

\section{Conclusion}

It has been shown in this paper that it is possible to detect cross peaks in a 2D DQF-COSY NMR spectrum when the relaxation times $T_{1}$ are very short and the lines in the conventional 1D NMR spectrum are consequently very broad. This is not the case for the conventional COSY NMR experiment. This case study demonstrates the feasibility of 2D DQF-COSY NMR experiments even in the case of very broad $(2.9-5.1 \mathrm{kHz})$ lines in the conventional 1D NMR spectrum. The present data complement the previously reported ${ }^{59} \mathrm{Co}-{ }^{59} \mathrm{Co} \mathrm{J}$ coupling constants and therefore refer to a quadrupolar nucleus. It is believed that other metal-to-metal scalar coupling constants involving quadrupolar nuclei may be obtained by simulation of COSY-type 2D NMR spectra. Particularly, this work opens up the possibility of investigating other ruthenium-based tetrahedral mixed-metal clusters with very broad peaks in the conventional 1D ${ }^{59} \mathrm{Co}$ NMR spectrum. It is also believed that the methodology described in this paper will be applicable to study metal clusters of biological relevance.

\section{Acknowledgements}

JR would like to thank the CNRS (Centre National de la Recherche Scientifique) for support. PK would like to thank the Research Committee (RC) of Rhodes University for financial aid.

\section{References}

[1] Jeener, J. (1971) Ampere International Summer School, Basko Polje, Yugoslavia.

[2] Reed, D. (1984) Applications of Two-Dimensional Nuclear Magnetic Resonance for the Boron Chemist. A COSY Study of Some Polyhedral Boranes. Journal of Chemical Research, 198-199.

[3] Venable, T.L., Hutton, W.C. and Grimes, R.N. (1984) Two-Dimensional Boron-11-Boron-11 Nuclear Magnetic Resonance Spectroscopy as a Probe of Polyhedral Structure: Application to Boron Hydrides, Carboranes, Metallaboranes and Metallacarboranes. Journal of the American Chemical Society, 106, 29-37. http://dx.doi.org/10.1021/ja00313a007

[4] Venable, T.L., Hutton, W.C. and Grimes, R.N. (1982) Atom Connectivities in Polyhedral Boranes Elucidated via Two-Dimensional J-Correlated Boron-11-Boron-11 FT NMR: A General Method. Journal of the American Chemical Society, 104, 4716-4717. http://dx.doi.org/10.1021/ja00381a053

[5] Hermanek, S., Fusek, J., Stibr, B., Plesek, J. and Jelinek, T. (1986) Elucidation of Structures of Nido-y-CB $\mathrm{C}_{12}$ and $\mathrm{B}_{9} \mathrm{H}_{12}^{-}$by Two-Diemnsional ${ }^{11} \mathrm{~B}^{-11} \mathrm{~B}$ NMR Spectroscopy. Polyhedron, 5, 1873-1879.

http://dx.doi.org/10.1016/S0277-5387(00)84871-8 
[6] Jacobsen, G.B., Meina, D.G., Morris, J.H., Thomson, C., Andrews, S.J., Reed, D., Welch, A.J. and Gaines, D.F. (1985) Studies of 2,5;6,10;8,10-Tri- $\mu$-hydro-nonahydro-nonaborate $\left(1^{-}\right),\left[\mathrm{B}_{9} \mathrm{H}_{12}\right]^{-}$: Preparation, Crystal and Molecular Structure, Nuclear Magnetic Resonance Spectra, Electrochemistry and Reactions. Journal of the Chemical Society, Dalton Transactions, 8, 1645-1654. http://dx.doi.org/10.1039/dt9850001645

[7] Fontaine, X.L.R., Fowkes, H., Greenwood, N.N., Kennedy, J.D. and Thornton-Pett, M. (1986) Pentamethylcyclopentadienylrhodaborane Chemistry. Part 1. High-Yield Planned Synthesis, Molecular Structure and Nuclear Magnetic Resonance Properties of the Ten-Vertex Nido-6-rhodadecaborane $\left[\left(\eta^{5}-\mathrm{C}_{5} \mathrm{Me}_{5}\right) \mathrm{RhB}_{9} \mathrm{H}_{13}\right]$. Journal of the Chemical Society, Dalton Transactions, 3, 547-552. http://dx.doi.org/10.1039/dt9860000547

[8] Fontaine, X.L.R., Fowkes, H., Greenwood, N.N., Kennedy, J.D. and Thornton-Pett, M. (1987) Pentamethylcyclopentadienylrhodaborane Chemistry. Part 2. The Reaction of [6- $\left(\eta^{5}-\mathrm{C}_{5} \mathrm{Me}_{5}\right)$-nido-6- $\left.\mathrm{RhB}_{9} \mathrm{H}_{13}\right]$ with Dimethyl Phenylphosphine and the Characterization of [5- $\left(\eta^{5}-\mathrm{C}_{5} \mathrm{Me}_{5}\right)-$ nido-5- $\left.\mathrm{RhB}_{9} \mathrm{H}_{11}-7-\left(\mathrm{PMe}_{2} \mathrm{Ph}\right)\right]$, [2- $\left(\eta^{5}-\mathrm{C}_{5} \mathrm{Me}_{5}\right)-$ closo-2- $\mathrm{RhB}_{9} \mathrm{H}_{7}-3,10-$ $\left.\left(\mathrm{PMe}_{2} \mathrm{Ph}\right)_{2}\right]$, and $\left[2-\left(\eta^{5}-\mathrm{C}_{5} \mathrm{Me}_{5}\right)\right.$-nido-2- $\left.\mathrm{RhB}_{8} \mathrm{H}_{10}-5-\left(\mathrm{PMe}_{2} \mathrm{Ph}\right)\right]$ by X-Ray Diffraction Analysis and Nuclear Magnetic Resonance Spectroscopy. Journal of the Chemical Society, Dalton Transactions, 6, 1431-1443. http://dx.doi.org/10.1039/dt9870001431

[9] Fontaine, X.L.R., Greenwood, N.N., Kennedy, J.D. and MacKinnon, P. (1988) Boron-11 and Proton Nuclear Magnetic Resonance Study of anti- $\mathrm{B}_{18} \mathrm{H}_{22}$ and Its Anions, Anti- $\left[\mathrm{B}_{18} \mathrm{H}_{21}\right]^{-}$and anti- $\left[\mathrm{B}_{18} \mathrm{H}_{20}\right]^{2-}$. The Crystal and Molecular Structure of $\left[\mathrm{NMe}_{4}\right]_{2}\left[\right.$ anti- $\left.\mathrm{B}_{18} \mathrm{H}_{20}\right]$. Journal of the Chemical Society, Dalton Transactions, 7, 1785-1793. http://dx.doi.org/10.1039/dt9880001785

[10] Goodreau, B.H. and Spencer, J.T. (1992) Small Heteroborane Cluster Systems. 5. Factors Affecting the $2 \mathrm{D}{ }^{11} \mathrm{~B}-{ }^{11} \mathrm{~B}$ (Boron-11) COSY NMR Spectra of Terminal- and Bridge-Substituted Pentaborane Cluster Systems. Inorganic Chemistry, 31, 2612-2621. http://dx.doi.org/10.1021/ic00038a056

[11] Domaille, P.J. (1984) The 1- and 2-Dimensional Tungsten-183 and Vanadium-51 NMR Characterization of Isopolymetalates and Heteropolymetalates. Journal of the American Chemical Society, 106, 7677-7687. http://dx.doi.org/10.1021/ja00337a004

[12] Moskau, D. and Günther, H. (1987) ${ }^{2} \mathrm{H},{ }^{2} \mathrm{H}-\mathrm{COSY}$ and ${ }^{2} \mathrm{H},{ }^{2} \mathrm{H},{ }^{13} \mathrm{C}-\mathrm{RELAY}$ NMR Experiments for the Analysis of Deuterated Compounds. Angewandte Chemie International Edition, 26, 156-157. http://dx.doi.org/10.1002/anie.198701561

[13] Günther, H., Moskau, D., Dujardin, R. and Maercker, A. (1986) ${ }^{6} \mathrm{Li}^{-}{ }^{6} \mathrm{Li}-\mathrm{Cosy}$-A New Tool for Structure Determinations of Lithium Organic Compounds in Solution. Tetrahedron Letters, 27, 2251-2254. http://dx.doi.org/10.1016/S0040-4039(00)84499-8

[14] Günther, H., Moskau, D., Bast, P. and Schmalz, D. (1987) Modern NMR Spectroscopy of Organolithium Compounds. Angewandte Chemie International Edition, 26, 1212-1220. http://dx.doi.org/10.1002/anie.198712121

[15] Moskau, D., Frankmölle, W., Eppers, O., Mons, H.-E. and Günther, H. (1994) Homonuclear Correlation Experiments with Quadrupolar Nuclei. Proceedings of the Indian Academy of Science, 106, 1471-1480.

[16] Barr, D., Clegg, W., Hodgson, S.M., Mulvey, R.E., Reed, D., Snaith, R. and Wright, D.S. (1988) A Li 8 Cluster of Three Edge-Connected $\mathrm{Li}_{4}$ Tetrahedra Held by $\mathrm{Li}-\mathrm{N}, \mathrm{Li} \mathrm{C}$, and $\mathrm{Li} \mathrm{Li}$ Interactions: Crystal Structure of (o$\left.\mathrm{LiC}_{6} \mathrm{H}_{4} \mathrm{CH}_{2} \cdot \mathrm{NLi} \cdot \mathrm{CH}_{2} \mathrm{CH}_{2} \mathrm{NMe}_{2}\right)_{4}$ and Detection of Metal Metal Coupling within It by ${ }^{7} \mathrm{Li}$ COSY n.m.r. Spectroscopy. Journal of the Chemical Society, Chemical Communications, 367-369.

[17] Kempgens, P., Raya, J., Elbayed, K., Granger, P., Rosé, J. and Braunstein, P. (2000) Theoretical Study of Two-Dimensional COSY Experiments for $S=7 / 2$ Spins: Application to ${ }^{59} \mathrm{Co}$ in the Tetrahedral Cluster $\mathrm{HFeCo}_{3}\left(\mathrm{CO}_{11} \mathrm{PPh}_{2} \mathrm{H}_{\text {. }}\right.$ Journal of Magnetic Resonance, 142, 64-73. http://dx.doi.org/10.1006/jmre.1999.1903

[18] Kempgens, P., Elbayed, K., Raya, J., Granger, P., Rosé, J. and Braunstein, P. (2006) Investigation of Tetrahedral Mixed-Metal Carbonyl Clusters by Two-Dimensional ${ }^{59}$ Co COSY and DQFCOSY NMR Experiments. Inorganic Chemistry, 45, 3378-3383. http://dx.doi.org/10.1021/ic051544a

[19] Kempgens, P. and Rosé, J. (2011) Determination of ${ }^{1} \mathrm{~J}\left({ }^{59} \mathrm{Co}-{ }^{59} \mathrm{Co}\right)$ Scalar Coupling Constants in the Tetrahedral MixedMetal Cluster $\mathrm{HFeCo}_{3}(\mathrm{CO})_{10}\left(\mathrm{PCyH}_{2}\right)\left(\mathrm{PPh}_{2}\left[\mathrm{CH}_{2} \mathrm{C}(\mathrm{O}) \mathrm{Ph}\right]\right)$ Using COSY-Type NMR Experiments. Journal of Magnetic Resonance, 209, 88-93. http://dx.doi.org/10.1016/j.jmr.2010.12.007

[20] Kempgens, P. (2010) The Theory of COSY NMR Experiments Revisited: Application to an AX Spin System of Quadrupolar Nuclei. Concepts in Magnetic Resonance Part A, 36A, 170-177. http://dx.doi.org/10.1002/cmr.a.20159

[21] Kempgens, P. (2010) The Theory of DQF-COSY NMR Experiments. I. Amplitude Modulation of the Signal. Concepts in Magnetic Resonance Part A, 36A, 341-346. http://dx.doi.org/10.1002/cmr.a.20168

[22] Kempgens, P. (2010) The Theory of DQF-COSY NMR Experiments. II. Phase Modulation of the Signal. A Simple Relationship between the Coefficients Needed to Calculate the COSY and DQF-COSY NMR Spectra of an AX Spin System of Quadrupolar Nuclei. Concepts in Magnetic Resonance Part A, 36A, 394-399.

http://dx.doi.org/10.1002/cmr.a.20167 
[23] Kempgens, P. (2011) The COSY and DQF-COSY NMR Spectra of an AX System of Spins $I=3 / 2$. Concepts in Magnetic Resonance Part A, 38A, 7-15. http://dx.doi.org/10.1002/cmr.a.20200

[24] Kempgens, P. (2011) The COSY and DQF-COSY NMR Spectra for Systems of Three Spins $I=7 / 2$. Concepts in Magnetic Resonance Part A, 38A, 74-83. http://dx.doi.org/10.1002/cmr.a.20209

[25] Braunstein, P., Oro, L.A. and Raithby, P.R. (1999) Metal Clusters in Chemistry. Wiley-VCH, Weinheim. http://dx.doi.org/10.1002/9783527618316

[26] Braunstein, P. and Rosé, J. (1995) 7-Catalysis and Related Reactions with Compounds Containing Heteronuclear Metal-Metal Bonds. In: Abel, E.W., Stone, F.G.A. and Wilkinson, G., Eds., Comprehensive Organometallic Chemistry, 2nd Edition, Pergamon Press, Oxford, 351-385. http://dx.doi.org/10.1016/B978-008046519-7.00091-5

[27] Braunstein, P. and Rosé, J. (1999) Heterometallic Clusters in Catalysis. In: Braunstein, P., Oro, L.A. and Raithby, P.R., Eds., Metal Clusters in Chemistry, Wiley-VCH, Weinheim. http://dx.doi.org/10.1002/9783527618316.ch2b

[28] Richert, T., Elbayed, K., Raya, J., Granger, P., Braunstein, P. and Rosé, J. (1996) ${ }^{59}$ Co NMR in Tetrahedral Clusters. Magnetic Resonance in Chemistry, 34, 689-696. http://dx.doi.org/10.1002/(SICI)1097-458X(199609)34:9<689::AID-OMR955>3.0.CO;2-U

[29] Braunstein, P., Rosé, J., Granger, P., Raya, J., Bouaoud, S.E. and Grandjean, D. (1991) Cobalt-59 NMR Study of Cluster Reactions: Solvent and Ligand Effects in Mixed-Metal, Tetrahedral $\mathrm{MCo}_{3}(\mathrm{M}=\mathrm{Iron}$, Ruthenium) Carbonyl Clusters. Crystal Structure of $\mathrm{FeCo}_{3}\left(\mu_{3}-\mathrm{H}\right)(\mu-\mathrm{CO})_{3}(\mathrm{CO})_{8}\left(\mathrm{PPh}_{2} \mathrm{H}\right)$. Organometallics, 10, 3686-3693. http://dx.doi.org/10.1021/om00056a046

[30] Matsuzaka, H., Kodama, T., Uchida, Y. and Hidai, M. (1988) The Chemistry of Heteronuclear Clusters and Homogeneous Multimetallic Catalysts. Part 8. Matallo-Slective Substitution Reaction by Amines or Phosphines in $\mathrm{HRuCo}_{3}(\mathrm{CO})_{12}$. Infrared and Proton and Cobalt-59 NMR Studies of $\mathrm{HRuCo}_{3}(\mathrm{CO})_{12}{ }^{\mathrm{x}} \mathrm{Lx}(\mathrm{L}=$ Amines or Phosphines; $\mathrm{x}$ $=0-2)$ and Crystal Structure $\mathrm{HruCo}_{3}(\mathrm{CO})_{11}\left(\mathrm{PPh}_{3}\right)$. Organometallics, 7, 1608-1613. http://dx.doi.org/10.1021/om00097a025

[31] Abragam, A. (1961) The Principles of Nuclear Magnetism. Oxford University Press, Oxford.

[32] Elbayed, K., Kempgens, P., Raya, J., Granger, P. and Rosé, J. (1998) Differential Line Broadening in the Presence of Quadrupolar-CSA Interference. Journal of Magnetic Resonance, 130, 209-216. http://dx.doi.org/10.1006/jmre.1997.1299

[33] Granger, P., Elbayed, K., Raya, J., Kempgens, P. and Rosé, J. (1995) 31P Differential Line Broadening in the Presence of the ${ }^{59}$ Co Quadrupolar-CSA Interference in Tetrahedral Clusters. Journal of Magnetic Resonance, Series A, 117, 179185. http://dx.doi.org/10.1006/jmra.1995.0726

[34] Carpenter, C., Kempgens, P., Hirschinger, J., Elbayed, K., Raya, J., Granger, P. and Rosé, J. (1996) 13th European Experimental NMR Conference, Paris, 19-24 May 1996.

[35] Kempgens, P., Hirschinger, J., Elbayed, K., Raya, J., Granger, P. and Rosé, J. (1996) Multinuclear NMR Study of $\mathrm{HFeCO}_{3}(\mathrm{CO})_{9}\left[\mathrm{P}\left(\mathrm{OCH}_{3}\right)_{3}\right]_{3}$ in the Solid State and in Solution. The Journal of Physical Chemistry, 100, 2045-2052. http://dx.doi.org/10.1006/jmre.1997.1299 